\title{
Christmas Present
}

\section{Dear Reader,}

When you are reading this magazine, the $118^{\text {th }}$ year of ATZ has left the starting grid. As you might expect, the publishers and the editorial team have made some good resolutions for 2016 and you are already looking at the first of them as a Christmas present. The international digital edition of ATZ and its sister magazines MTZ and ATZelektronik are now available as genuine and complete e-magazines. As a subscriber to our English-written ATZworldwide edition, in the past you have been able to read the English versions of technical articles in PDF format. Now we step on it and are offering you even more content. From now on, our "In the Spotlight" feature, an interview relating to our cover story, news about companies and new products as well as a guest commentary column and, of course, the familiar articles on the industry and the latest developments in the field of research will be available for you to read in a user-friendly format with new functions.

In concrete terms, this means that you can access the international electronic magazine from any modern web browser, regardless of the operating system, and on PCs, tablets and smartphones. The HTML5 standard will also allow us to include multimedia content in future, which means that we can offer you genuine added value. The interactive contents page enables you to move quickly to the content you want to read. Using the search function enables you to search the entire issue rapidly for a specific keyword. In addition, you can access social media sites directly from every page, which will allow you to tell your colleagues about interesting
ATZworldwide articles. Of course, you can also save the content in PDF format and print it out in the familiar way and, as usual, you can access it from www.ATZ-worldwide.com. All the 2015 issues are now available as e-magazines and, naturally, you can still use the PDF archive.

We would be grateful if you could inform your colleagues all over the world about the new international e-magazine. You will soon be able to find out more about our remaining resolutions.

With best regards and to a good start in the New Year,

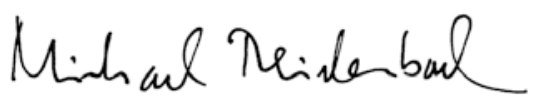

Dipl.-Ing. Michael Reichenbach Deputy Editor in Chief

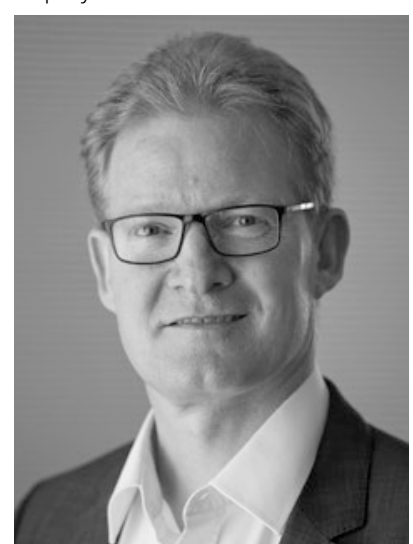

